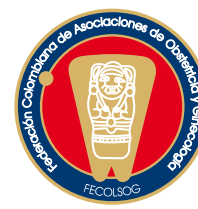

EDITORIAL

\title{
LA REVISTA COLOMBIANA DE OBSTETRICIA Y GINECOLOGÍA Y LA EDUCACIÓN MÉDICA EN MEDICINA BASADA EN LA EVIDENCIA
}

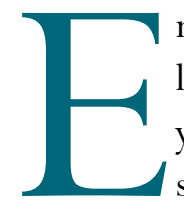

n el presente número y a partir del mismo, la Revista Colombiana de Obstetricia y Ginecología se propone publicar una serie de artículos de educación médica con el objetivo de capacitar a nuestros lectores en la comprensión de los conceptos básicos y en la interpretación y aplicación de los estimadores epidemiológicos más utilizados en la medicina basada en la evidencia (MBE).

Algunos colegas consideran que el uso de la MBE es poco conveniente porque: no reconoce la experiencia como fuente de conocimiento, su complejidad requiere sólidos conocimientos de epidemiología clínica para una correcta interpretación y aplicación de los estimadores epidemiológicos, ha complicado el ejercicio de la medicina actual e incrementa los costos. ${ }^{1}$

De otro lado, el ejercicio de la medicina en la actualidad se encuentra enmarcado en el uso de tecnologías en constante evolución. Como ejemplo, se observan las imágenes que permiten estudiar con gran detalle las estructuras internas del cuerpo humano, ${ }^{2} \mathrm{e}$ inclusive, las estructuras fetales durante el embarazo ${ }^{3}$ o las técnicas de biología molecular con las cuales se realiza la identificación de infecciones virales, como en el caso de las pruebas de tamizaje en cáncer. ${ }^{4}$ Estas técnicas, inimaginables hace 30 años, hacen parte de las alternativas diagnósticas de las cuales se dispone hoy en día a nivel individual o poblacional. Por otra parte, cada vez hay más medicamentos, algunos de alto costo y con indicaciones novedosas, los cuales se comienzan a distribuir antes de que se haya hecho una evaluación cuidadosa de sus beneficios, riesgos y costo-efectividad en el contexto local. ${ }^{5}$ Actualmente, la información no es un privilegio de los profesionales de la salud, por el contrario, ésta está al alcance del público en general. Por medio de la Internet, por ejemplo, los pacientes y sus familiares pueden acceder a información respecto a las últimas tecnologías relacionadas con su problema de salud. ${ }^{6}$ Son estas situaciones las que hacen que el trabajador de la salud necesite conocer, no sólo las tecnologías de punta, sino también qué tan útiles son éstas, en especial aquellas utilizadas con mayor frecuencia.

La MBE busca complementar el buen criterio que brinda la experiencia con las pruebas que soportan el desempeño de las tecnologías empleadas en este quehacer diario. Permite identificar el problema a enfrentar, hacer la selección y el análisis crítico de la literatura disponible al respecto, y resumir y almacenar esta literatura de manera eficiente. ${ }^{1}$ Por el contrario, renunciar al uso de la MBE no parece una buena decisión en el contexto del ejercicio médico actual, enmarcado, como se mencionó antes, en el alto volumen de información disponible ${ }^{1}$ (en especial de literatura médica), en las restricciones impuestas por las aseguradoras al uso de ciertas tecnologías, en las presiones de la industria para una mayor utilización de éstas y, por último, en el riesgo de demandas ante los malos resultados en salud. ${ }^{?}$

De esta manera, la Revista Colombiana de Obstetricia y Ginecología, publicación oficial de la FECOLSOG, cumple con el objetivo misional de contribuir en la educación médica de sus afiliados. Además, invita a los diferentes autores que asisten a la misma a que participen en esta sección para que a partir de problemas en la práctica cotidiana, se 
desarrollen ejemplos de aplicación de los conceptos de la MBE que permitan a los lectores tener mejores elementos para aproximarse de manera crítica a la información médica disponible.

\section{Hernando Gaitán D., M.D., MSc}

Editor

\section{REFERENCIAS}

1. Straus S, Richardson WS, Glasziou P, Haynes B. Introduction. En: Straus S, Richardson WS, Glasziou P, Haynes B, editors. Evidence Based Medicine: how to practice and to teach EBM. 3rd ed. Edinburg: Elsevier; 2005. p 1-12.

2. Lax A, Prince MR, Mennitt KW, Schwebach JR, Budorick NE.The value of specific MRI features in the evaluation of suspected placental invasion. Magn Reson Imaging 2007;25:87-93.
3. Gagnon A, Wilson RD, Allen VM, Audibert F, Blight $\mathrm{C}$, Brock JA, et al. Evaluation of prenatally diagnosed structural congenital anomalies. J Obstet Gynaecol Can 2009;31:875-81

4. Naucler P, Ryd W, Törnberg S, Strand A, Wadell G, Elfgren K, et al. Efficacy of HPV DNA testing with cytology triage and/or repeat HPV DNA testing in primary cervical cancer screening. J Natl Can Inst 2009;101:88-99.

5. Reynales-Shigematsu LM, Rodrigues ER, LazcanoPonce E. Cost-effectiveness analysis of a quadrivalent human papilloma virus vaccine in Mexico. Arch Med Res 2009;40:503-13.

6. Medline plus. Biblioteca Nacional de Medicina de los EE UU y los Institutos Nacionales de Salud. Visitado en 2009 Dic 1. Disponible en: http://medlineplus. gov/spanish/

7. Perrier J. Relación gremial con las aseguradoras. Rev Chilena de Cirugía 2008;60:357-62. 